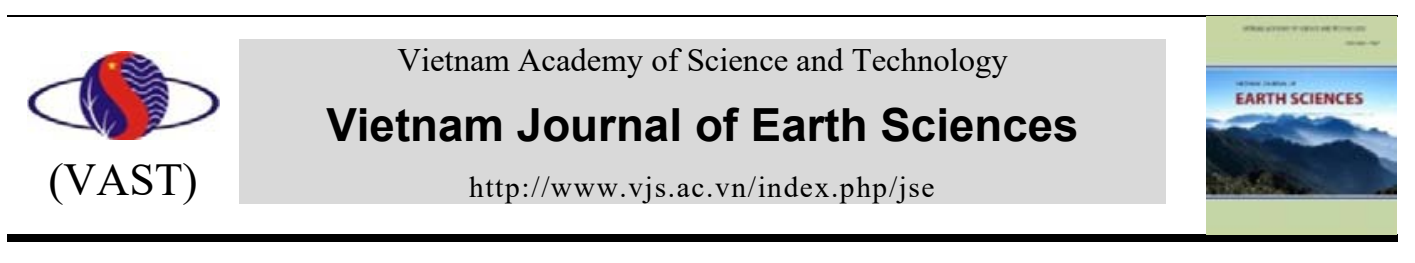

\title{
Determination of ground displacement of 25 April 2015 Nepal earthquake by GNSS precise point positioning
}

\author{
Nguyen Ngoc Lau \\ Ho Chi Minh City University of Technology, Vietnam \\ Received 5 May 2017; Received in revised form 26 October 2017; Accepted 10 November 2017
}

\begin{abstract}
The April 2015 Nepal earthquake (known as the Gorkha earthquake) occurred at 06:11:25 (UTC) on the 25th of April, with a magnitude of $7.8 \mathrm{Mw}$. It was the worst natural disaster to strike Nepal since the 1934 Nepal-Bihar earthquake. Precise determination of ground displacement in this area will provide important information to better understand the structure and scope of the earthquake, contributing to faster and more accurate earthquake prediction. In this paper, we use precise point positioning to determine the displacements of 17 GNSS stations around the epicenter for the day of the earthquake. The processing results show that the common displacement direction is close to southsouthwest with the largest value being approximately $2 \mathrm{~m}$ and the affected area being about $160 \mathrm{~km}$ in the southeast direction centered around the earthquake epicenter. However, a detectable GNSS signal was still observed at a station some $647 \mathrm{~km}$ away from the epicenter.
\end{abstract}

Keywords: April 2015 Nepal earthquake; GNSS; PPP.

(C)2018 Vietnam Academy of Science and Technology

\section{Introduction}

The Gorkha earthquake killed more than 9,000 people and injured more than 23,000 . It occurred at 06:11:25 (UTC) on 25 April 2015, with a magnitude of $7.8 \mathrm{Mw}$ or $8.1 \mathrm{Ms}$ and a maximum Mercalli Intensity of IX. Its epicenter locates at the east of the district of Lamjung, latitude $28.231^{\circ} \mathrm{N}$, longitude $84.731^{\circ} \mathrm{E}$ and at a depth of approximately $8.2 \mathrm{~km}$. It was the worst natural disaster to strike Nepal since the 1934 Nepal-Bihar earthquake. According to the United States Geological Survey (USGS) (USGS, 2015), the Gorkha earthquake occurred as the result of thrust faulting on or near the main frontal thrust between the

"Corresponding author, Email: nnlau@hcmut.edu.vn subducting Indian plate and the overriding Eurasian plate to the north. At the location of this earthquake, approximately $80 \mathrm{~km}$ to the northwest of the Nepalese capital of Kathmandu, the Indian plate is converging to the Eurasian plate at a rate of $45 \mathrm{~mm} /$ year towards the north-northeast, driving the uplift of the Himalayan mountain range.

Geophysicists and other experts had warned for decades that Nepal was vulnerable to a deadly earthquake, particularly because of its geology, urbanization, and architecture. For this reason, some scientific organizations had set up instruments and facilities to monitor earthquake activity over this region. University Navstar Consortium (UNAVCO), a non-profit university-governed consortium, facilitates geoscience research and education 
using geodesy, is currently supporting retrieval of high-rate and standard Global Navigation Satellite System (GNSS) data from stations within Nepal (UNAVCO, 2015). These data can be accessed through the UNAVCO Data Archive as they become available (Figure 1).

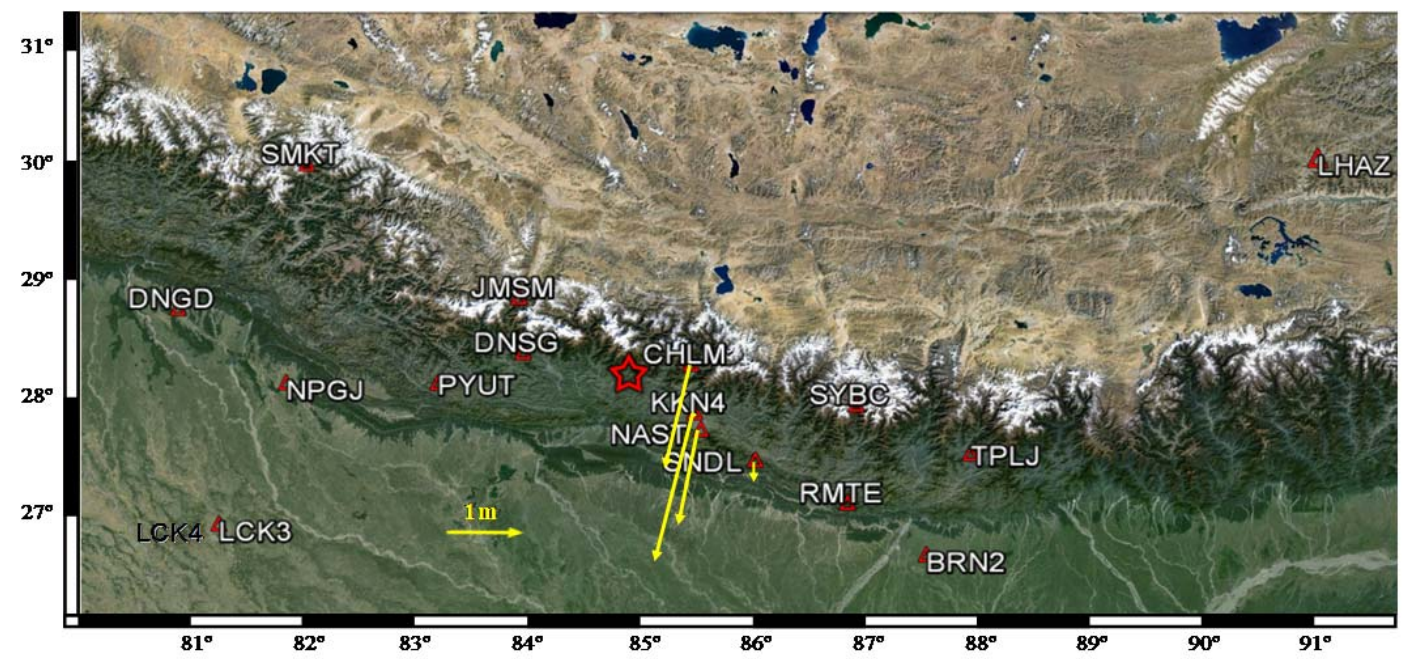

Figure 1. Epicenter (star) and GNSS station (triangle) displacement vectors

With UNAVCO support, we collected some GNSS data from 17 GNSS stations around the epicenter on the day of the earthquake. These stations are listed in Table 1 and Figure 1. This permanent GNSS station network is a favorable condition for applying existing GNSS positioning methods to accurately determine the displacement of the station over time.

Data on recent earthquakes have also been collected and processed using GNSS (Ji C. et al., 2004; Yue H. et al., 2013). In Vietnam there is also similar research on the Tohoku earthquake in Japan on March 11, 2011 (Nguyen Ngoc Lau, 2012). However, only at the Gorkha event, can scientists first observe earthquakes occurring in an area with many high-rate GNSS stations near the epicenter and covering the affected area completely (Galetzka J. et al., 2015).

The displacement of a set of stations over the earthquake area is an important source of information that provides quantitative data for a better understanding of tectonic activity in the area. This can help to make earthquake prediction faster, more accurate, and prevent similar disasters.

To accurately determine the displacement of each GNSS measurement station, the coordinates of the stations over time are determined by the GNSS processing in relative or absolute terms. If an earthquake occurs and moves the station, we can calculate the displacement by comparing its coordinates before and after the earthquake.

The GNSS relative (or differential) method was mainly used in the 1980s and early 1990s, when GNSS absolute method had not yet achieved the desired accuracy. The disadvantage of this method is that it is difficult to provide high positioning accuracy when handling long baselines. We have applied the relative method to calculate the ground displacement caused by the Tohoku earthquake in Japan on 11-03-2011 (Nguyen Ngoc Lau, 2012). In order to handle the long baselines of up to $1000 \mathrm{~km}$, we had to apply special techniques to simultaneously process GPS and GLONASS measurements to get the desired accuracy (Nguyen Ngoc Lau et al., 2011).

GNSS Precise Point Positioning (also known as PPP) is being used today to gradual- 
Vietnam Journal of Earth Sciences, 40(1), 17-25

ly replace the relative method. The reason is that its positioning accuracy is increasingly improved and its advantages compared to relative method. PPP is also the method we choose to use for this paper. It will therefore be introduced in more detail in Section 2.

\section{GNSS precise point positioning method}

GNSS PPP is a positioning method that processes phase and code measurements from a single GNSS receiver together with precise GNSS orbit and clock correction products. PPP can provide a common position accuracy of centimeter level in $24 \mathrm{~h}$ static and decimeter level in kinematic modes (Zumberge J.F. et al., 1997; King M. et al., 2002). The most prestigious organization providing precise GNSS orbit and clock products for civilian users is the International GNSS Service (IGS) (Kouba J., 2009).

PPP has an advantage over traditional differential techniques in that the method removes the need for the user to establish a local base station. Therefore, the spatial operating range limit of differential techniques is negated, as well as the need for simultaneous observations at both rover and base for realtime applications (King M. et al., 2002).

In recent years, the accuracy of PPP has improved gradually because the quality of GNSS orbit and clock correction products have been enhanced, and the number of GNSS has increased rapidly. PPP with multi-GNSS potentially can provide an accuracy of better than $1 \mathrm{~cm}$ in $24 \mathrm{~h}$ static and better than 1 decimeter in kinematic modes (Rabbou M.A. et al., 2015; Afifi A. et al., 2016). With such an accuracy, PPP can be used to detect any displacements larger than several decimeters in station coordinates.

The current direction of PPP development is real-time positioning and improvement of positioning accuracy. The direction to improve accuracy for PPP focuses on resolving ambiguity for carrier phase measurements (Geng J. et al., 2012) and processing mixed measurements from multi-GNSS such as GPS, GLONASS, GALILEO, BEIDOU (Rabbou MA et al., 2015; Afifi A. et al., 2016).
In Vietnam, we have researched PPP since 2010 with GPS only (Nguyen Ngoc Lau, 2009; 2010), and then expanded to GPS and GLONASS (Nguyen Ngoc Lau et al., 2012, Nguyen Ngoc Lau, 2013).

PPP method has been described in detail in many documents (Nguyen Ngoc Lau, 2009, Nguyen Ngoc Lau et al., 2010; 2012, Nguyen Ngoc Lau, 2013). So in this article, we only mention our self-developed PPP software package, the so-called PPPC. This is the product of two ministry-level projects chaired by us (Nguyen Ngoc Lau et al., 2010; 2012). PPPC version 3.2 can process code and phase measurements from GPS, GLONASS, GALILEO and BEIDOU satellite systems for both static and kinematic modes. Using PPPC to process GPS + GLONASS data at some IGS stations has proven that positioning accuracy is better than $2 \mathrm{~cm}$ for $1 \mathrm{~h}$ static data and better than 1 cm with 24 hours (Nguyen Ngoc Lau, 2013).

With particularly advantage, PPPC is able to estimate coordinates before and after an indicated epoch. This option is very suitable for precise calculation of station coordinate slips if they have occurred. We use PPPC to process GNSS data in Table 1.

Table 1. GNSS stations are located around the Earthquake epicenter

\begin{tabular}{|c|c|c|c|c|}
\hline No. & $\begin{array}{l}\text { GNSS } \\
\text { Station }\end{array}$ & $\begin{array}{c}\text { Interval } \\
(\mathrm{sec})\end{array}$ & $\begin{array}{l}\text { GNNS satellite } \\
\text { systems }\end{array}$ & $\begin{array}{l}\text { Distance to } \\
\text { the epicenter } \\
(\mathrm{km})\end{array}$ \\
\hline 1 & $\overline{\text { CHLM }}$ & 15 & $\overline{\text { GPS }}$ & 56 \\
\hline 2 & KKN4 & 15 & GPS & 68 \\
\hline 3 & NAST & 15 & GPS & 81 \\
\hline 4 & DNSG & 15 & GPS & 94 \\
\hline 5 & JMSM & 15 & GPS & 119 \\
\hline 6 & SNDL & 15 & GPS & 137 \\
\hline 7 & PYUT & 15 & GPS & 169 \\
\hline 8 & SYBC & 15 & GPS & 202 \\
\hline 9 & SMKT & 15 & GPS & 348 \\
\hline 10 & RMTE & 15 & GPS & 227 \\
\hline 11 & NPGJ & 15 & GPS & 305 \\
\hline 12 & TPLJ & 15 & GPS & 310 \\
\hline 13 & BRN2 & 15 & GPS & 311 \\
\hline 14 & LCK3 & 30 & GPS, GLONASS & 394 \\
\hline 15 & LCK4 & 30 & GPS + GLONASS & 394 \\
\hline 16 & DNGD & 15 & GPS & 411 \\
\hline 17 & LHAZ & 30 & GPS + GLONASS & 647 \\
\hline
\end{tabular}




\section{Results}

Firstly, we use PPPC to process all of the GNSS stations in the kinematic mode with some options as follows:

- Using IGS precise orbit and clock corrections;

- Using P3 code and L3 carrier phase measurements of GPS and GLONASS (only for LCK3, LCK4 and LHAZ);

- Setting the elevation cut off angle as $5^{\circ}$;

- Estimating one tropospheric zenith delay every 2.5 hours with the Niell mapping function;

- Applying IGS08 antenna model and solid Earth model.

After screening the processed station coordinates epoch by epoch, we detect 4 stations which have large slip values at epoch 6:12:15 (GPST) as shown in Figure 2. Therefore at the time of the earthquake (6:11:25 UTC $6: 11: 41$ GPST), the stations were not affected immediately. The shift starts only about 26 seconds later.
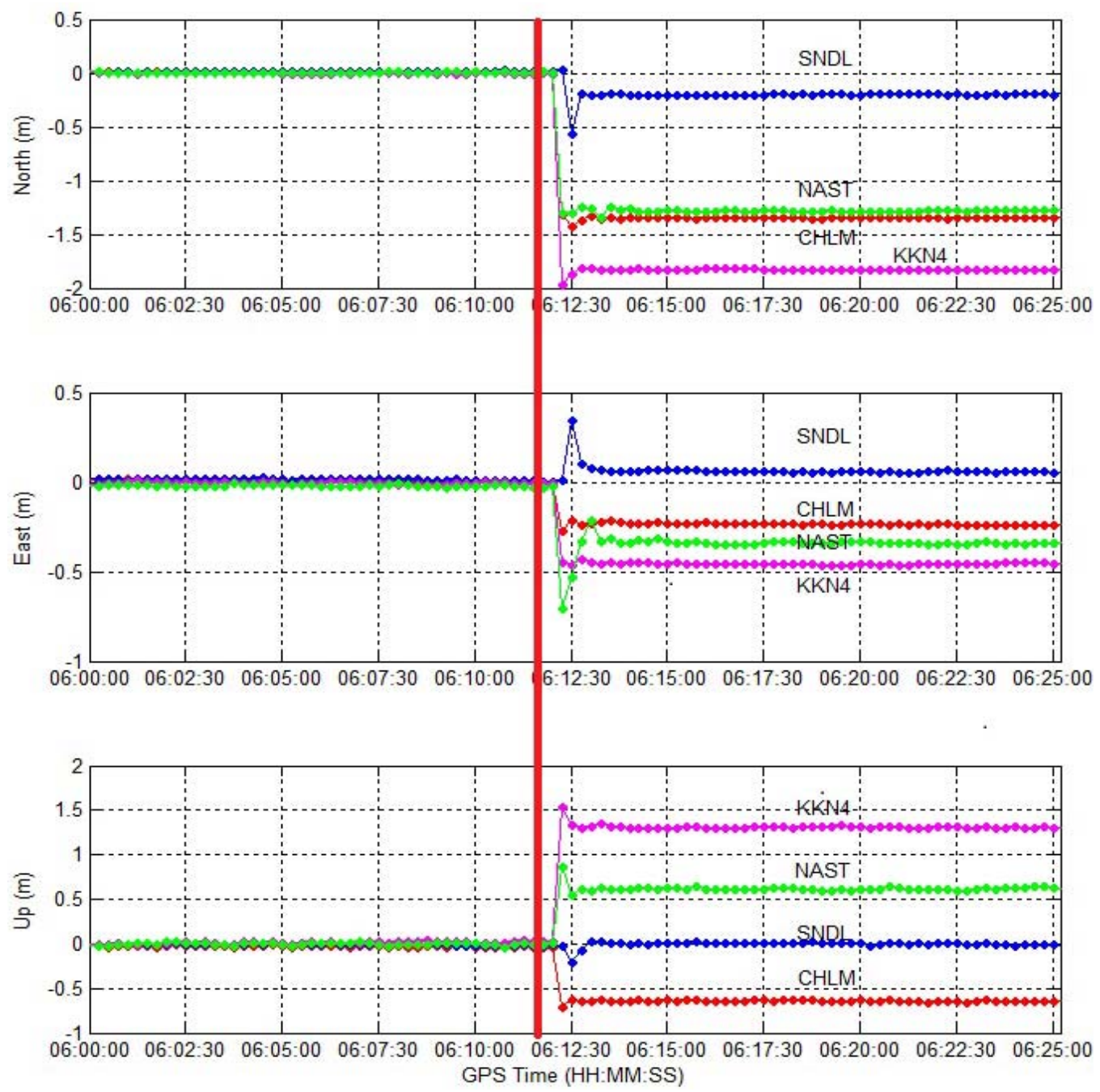

Figure 2. Station displacements by using PPPC in kinematic mode. Vertical bar indicates the earthquake epoch 
Vietnam Journal of Earth Sciences, 40(1), 17-25

Since GNSS epoch solutions have an accuracy at the decimeter level, it is not sufficient for precise calculation of station displacements. We re-processed the GNSS data by using PPPC in static mode for epochs before and after epoch 6:12:15. As a result, the displacement of each station is calculated by subtracting two processed station coordinates before and after epoch 6:12:15. These results are given in Table 2.

Table 2. Displacements of GNSS stations at epoch 6:12:15

\begin{tabular}{|c|c|c|c|c|}
\hline \multirow{2}{*}{ No. } & \multirow{2}{*}{ GNSS Station } & \multicolumn{3}{|c|}{ Displacements (m) } \\
\hline & & North & East & Up \\
\hline 1 & CHLM & $-1.380 \pm 0.001$ & $-0.220 \pm 0.005$ & $-0.590 \pm 0.007$ \\
\hline 2 & KKN4 & $-1.827 \pm 0.002$ & $-0.455 \pm 0.005$ & $+1.279 \pm 0.009$ \\
\hline 3 & NAST & $-1.293 \pm 0.002$ & $-0.318 \pm 0.006$ & $+0.623 \pm 0.009$ \\
\hline 4 & DNSG & $+0.004 \pm 0.003$ & $+0.006 \pm 0.008$ & $+0.003 \pm 0.015$ \\
\hline 5 & JMSM & $-0.006 \pm 0.002$ & $+0.003 \pm 0.005$ & $+0.004 \pm 0.008$ \\
\hline 6 & SNDL & $-0.220 \pm 0.001$ & $+0.045 \pm 0.004$ & $+0.064 \pm 0.006$ \\
\hline 7 & PYUT & $+0.001 \pm 0.001$ & $-0.005 \pm 0.004$ & $+0.012 \pm 0.006$ \\
\hline 8 & SYBC & $-0.015 \pm 0.002$ & $-0.010 \pm 0.005$ & $+0.003 \pm 0.009$ \\
\hline 9 & SMKT & $+0.001 \pm 0.002$ & $-0.002 \pm 0.004$ & $-0.002 \pm 0.006$ \\
\hline 10 & RMTE & $-0.000 \pm 0.001$ & $-0.005 \pm 0.004$ & $+0.004 \pm 0.005$ \\
\hline 11 & NPGJ & $+0.002 \pm 0.002$ & $-0.012 \pm 0.004$ & $+0.008 \pm 0.006$ \\
\hline 12 & TPLJ & $+0.002 \pm 0.001$ & $-0.001 \pm 0.004$ & $+0.002 \pm 0.006$ \\
\hline 13 & BRN2 & $+0.001 \pm 0.001$ & $-0.003 \pm 0.005$ & $+0.000 \pm 0.006$ \\
\hline 14 & LCK3 & $+0.002 \pm 0.001$ & $-0.011 \pm 0.002$ & $+0.012 \pm 0.003$ \\
\hline 15 & LCK4 & $+0.003 \pm 0.001$ & $-0.011 \pm 0.002$ & $+0.010 \pm 0.003$ \\
\hline 16 & DNGD & $+0.002 \pm 0.001$ & $-0.002 \pm 0.002$ & $-0.018 \pm 0.002$ \\
\hline 17 & LHAZ & $+0.004 \pm 0.001$ & $-0.007 \pm 0.002$ & $+0.007 \pm 0.003$ \\
\hline
\end{tabular}

Table 2 shows that there are only 4 GNSS stations affected by the earthquake including CHLM, KKN4, NAST and SNDL. Where KKN4 was shifted nearly $2 \mathrm{~m}$ in the horizontal component, SNDL is some $177 \mathrm{~km}$ from the epicenter but also moved horizontally more than $0.2 \mathrm{~m}$. Some closer stations, such as DNSG and JMSM distributed in the northwest, are seemingly not affected. This shows that the affected area is stretched in the southeast direction.

Figure 3 shows the north, east and up series of 4 GNSS stations distributed eastsoutheast of the epicenter, including SYBC, RMTE, TPLJ and BRN2. The timing of the earthquake-induced movement is well documented on the charts of the stations. It is not fixed but varies with the distance to the epi- center. The time of movement of the stations SYBC and RMTE about $200 \mathrm{~km}$ from the epicenter is 6:13:00 GPST. Stations TPLJ and BRN2, about $300 \mathrm{~km}$ from the epicenter, are 6:13:15 GPST.

Figure 4 presents the processing results of the farthest GNSS station - the LHAZ $(647 \mathrm{~km})$. Watching the sequence of this station coordinates over time, we can still observe the effects of the earthquake occurring at 6:15:00 GPST, which is about 3 minutes slower than the stations in Figure 2 and almost 2 minutes compared to the stations in Figure 3.

We present displacement vectors of the affected stations on Figure 1 and see clearly that the common moving direction of GNSS stations is close to the south-southwest. 
Nguyen Ngoc Lau/Vietnam Journal of Earth Sciences 40 (2018)
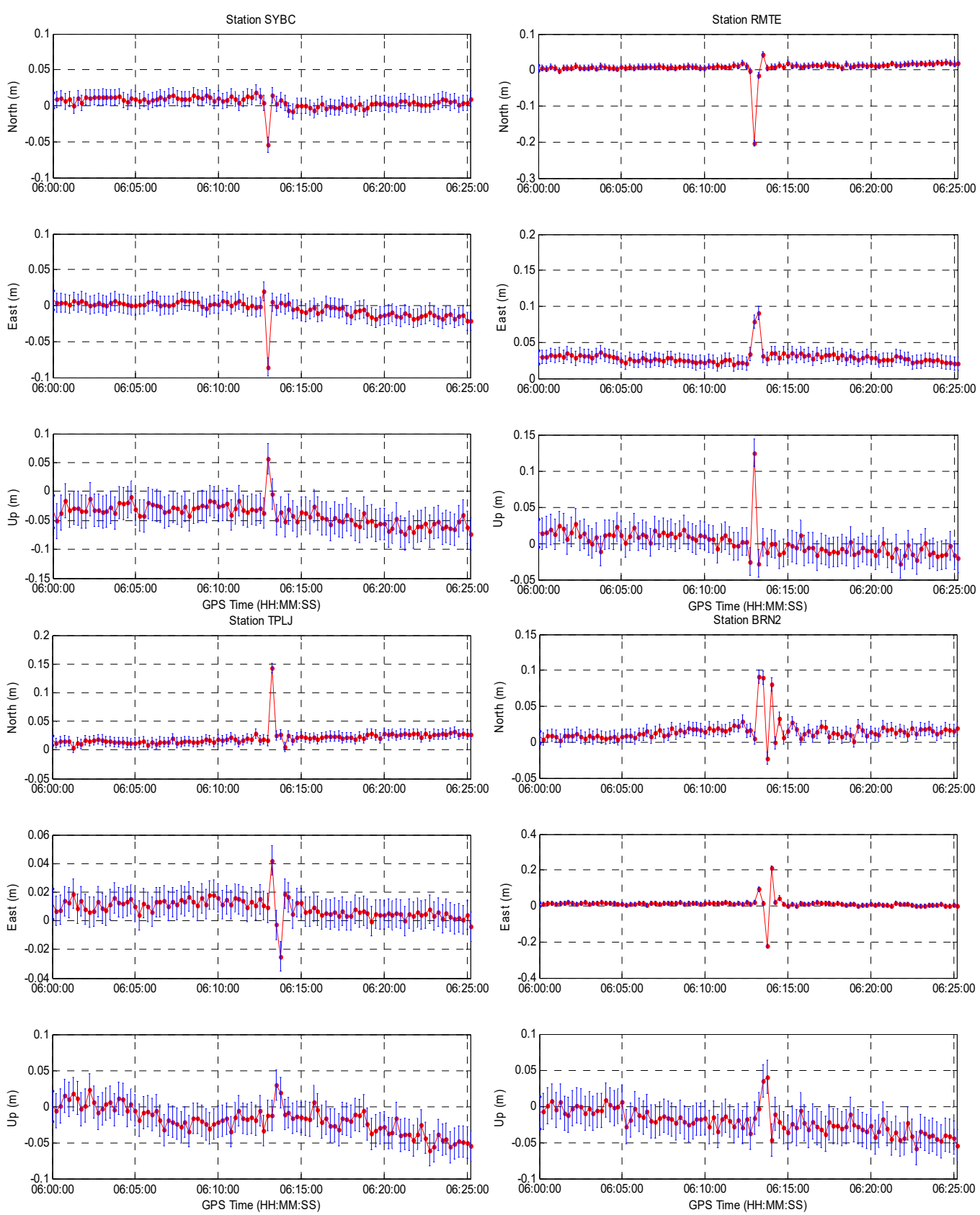

Figure 3. The coordinate series over time of the 4 GNSS stations are distributed east-southeast of the epicenter 
Vietnam Journal of Earth Sciences, 40(1), 17-25

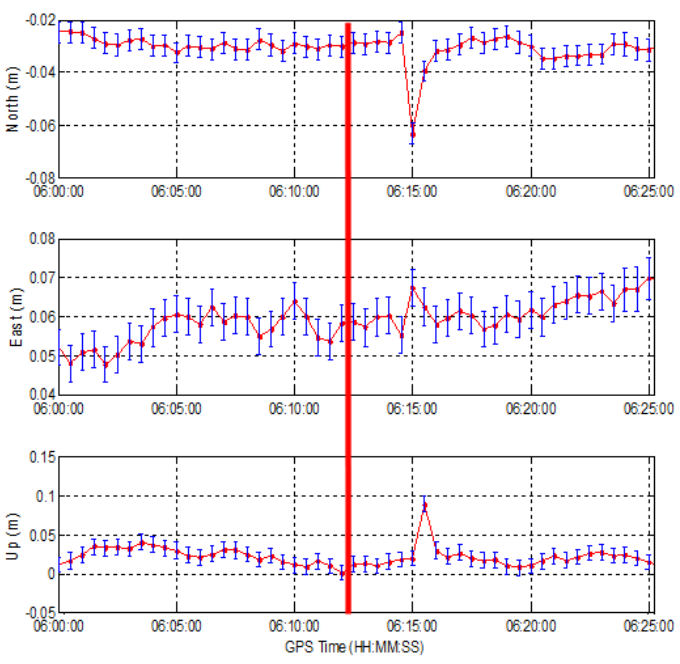

Figure 4. The time series of the LHAZ station. Vertical bar indicates the earthquake epoch

\section{Discussions}

Jianghui Geng in (Geng J., 2015) used GAMIT software to process relatively the GNSS data. His processing results of stations KKN4 and NAST are given in Figure 5. The visual estimates of displacement are -1.8, $0.45,+1.3$ in the north, east and up components for KKN4 and $-1.3,-0.3,+0.6$ for

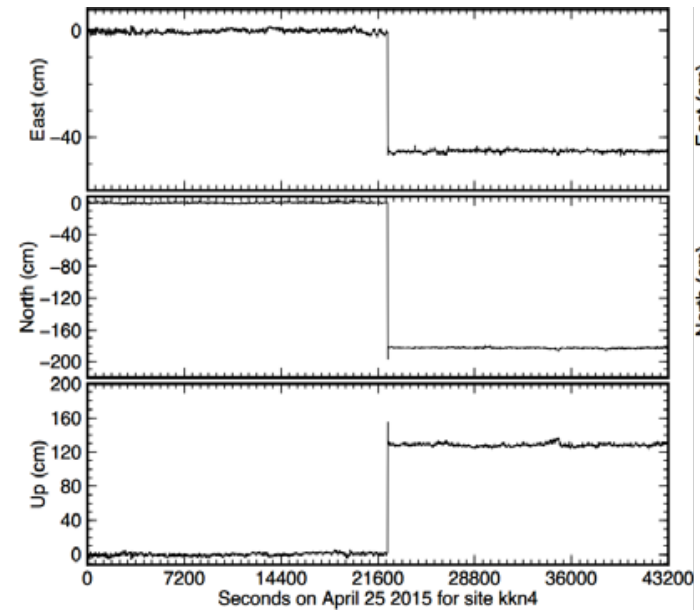

Figure 5. Jianghui Geng's processing results of stations KKN4 (left) and NAST (right), accepted from (Geng J., 2015)

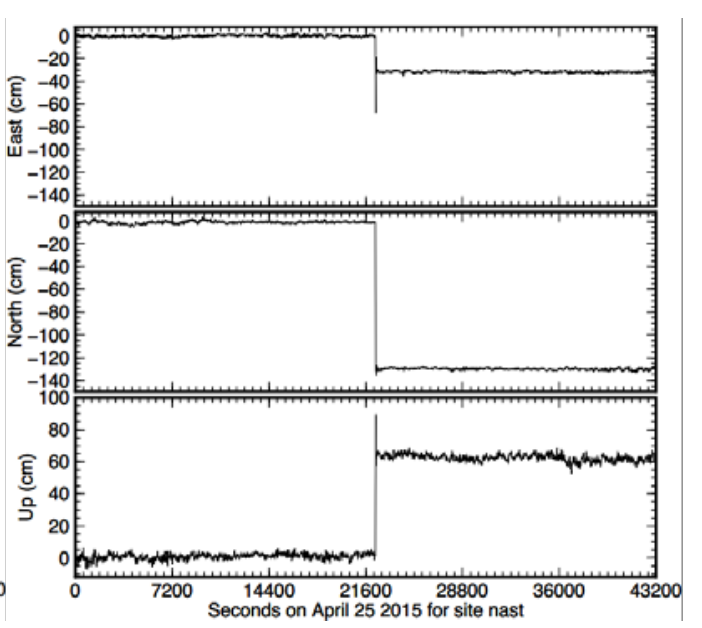

NAST. These results agree with our results in Table 2.

In (Lemmens M., 2015), Lemmens analyzed the $5 \mathrm{~Hz}$ GPS data processing results of Galetzka et al., 2015) at two stations KKN4 and NAST. He concluded that the north and eastward movements of the two stations were distinctly different behaviors (Figure 6) because the KKN4 station was located on hard rock, while NAST installed on sediment in the valley Kathmandu. NAST shows prolonged sediment resonance with a sweeping path of almost $2 \mathrm{~m}$.

By applying a ScanSAR-based interferometry analysis of Advanced Land Observing Satellite 2 (ALOS-2) L-band data, Kobayashi et al. (Kobayashi T. et al., 2015) had similar conclusions that "a major displacement area extends with a length of about $160 \mathrm{~km}$ in the east-west direction, and the most concentrated crustal deformation with ground displacement exceeding $1 \mathrm{~m}$ is located $20-30 \mathrm{~km}$ east of Kathmandu". However, this technique does not provide precise coordinate displacement values, unlike the GNSS PPP technique. 

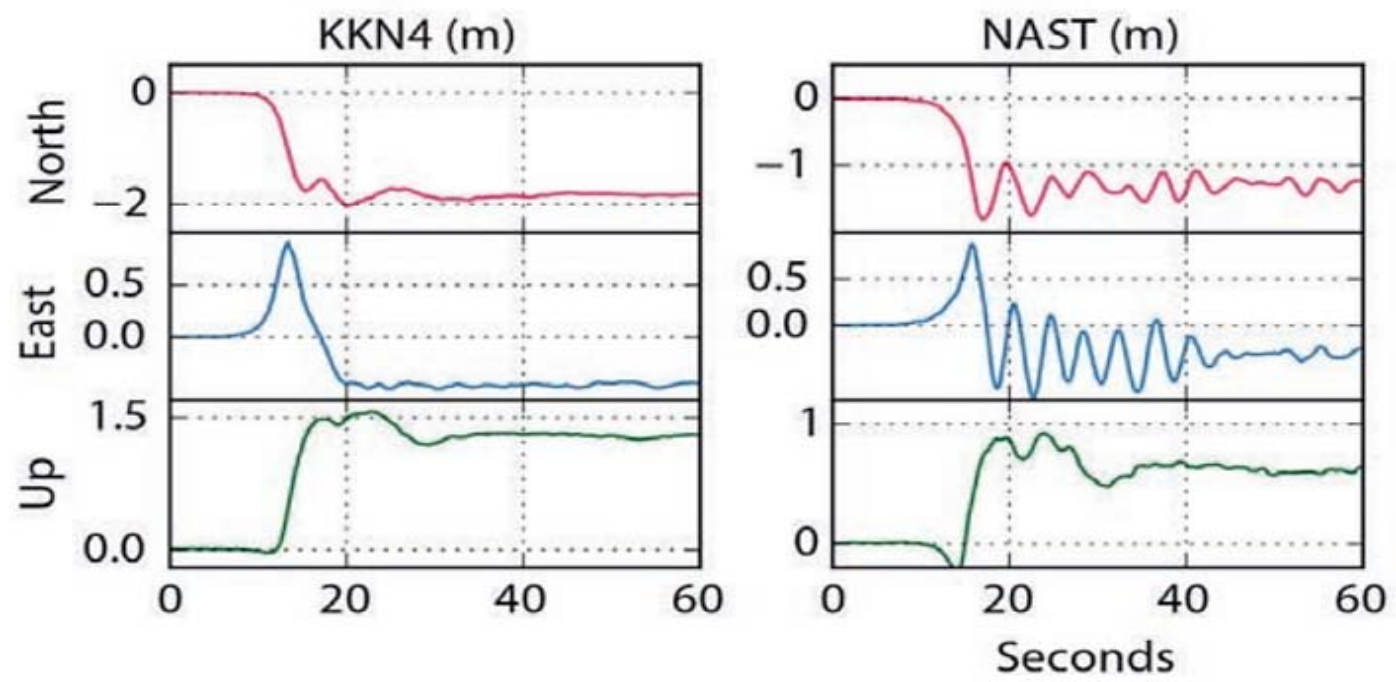

Figure 6. Displacements of stations KKN4 (left) and NAST (right), accepted from (Galetzka J., 2015)

\section{Conclusions}

To monitor the effect of the earthquake with the magnitude of 7.8 on 25 April 2015 in Nepal, we collected and processed GNSS data at 17 stations around the epicenter by using the GNSS PPPC method. The GNSS station displacements are calculated precisely with an accuracy of $1 \mathrm{~cm}$ in the horizontal and the vertical components. These displacements show that the affected area stretches about $160 \mathrm{~km}$ in the south-east. The common moving direction is close to the south-southeast with the maximum value of $2 \mathrm{~m}$ in the horizontal component.

Our results are similar to other studies using different data sources or different processing methods such as GNSS relative (Geng J., 2015), high rate GNSS PPP (Galetzka J. et al., 2015; Lemmens M., 2015) and ScanSAR (Kobayashi T. et al., 2015).

In conclusion, the GNSS PPP method has proven its advantages for monitoring ground movements due to earthquakes such as position accuracy, large area coverage, availability, short-term or long-term displacement tracking.
In order to have the better determination of ground displacements, our future research direction will continue to focus on improving the positioning accuracy of GNSS PPP on the basis of ambiguity resolution of carrier phase measurements, and apply to our PPPC software.

\section{References}

Akram Afifi, Ahmed El-Rabbany, 2016. Improved Between-Satellite Single-Difference Precise Point Positioning Model Using Triple GNSS Constellations: GPS, Galileo, and Beidou, Positioning, 7, 63-74. Doi.org/10.4236/pos.2016.72006.

Galetzka J., Melgar D., Genrich J.F., Geng J., Owen S., Lindsey E.O., Xu X., Bock Y., Avouac J.-P., Adhikari L.B., Upreti B.N., Pratt-Sitaula B., Bhattarai T.N., Sitaula B.P., Moore A., Hudnut K.W., Szeliga W., Normandeau J., Fend M., Flouzat M., Bollinger L., Shrestha P., Koirala B., Gautam U., Bhatterai M., Gupta R., Kandel T., Timsina C., Sapkota S.N., Rajaure S., Maharjan N., 2015. Slip pulse and resonance of the Kathmandu basin during the 2015 Gorkha earthquake, Nepal, Science, 349, 1091-1095. Han Yue, Thorne Lay, Susan Y. Schwartz, Luis Rivera, Marino Protti Timothy H. Dixon, Susan Owen, and 
Vietnam Journal of Earth Sciences, 40(1), 17-25

Andrew V. Newman, 2013, The 5 September 2012 Nicoya, Costa Rica Mw 7.6 earthquake rupture process from joint inversion of high-rate GPS, strongmotion, and teleseismic $\mathrm{P}$ wave data and its relationship to adjacent plate boundary interface properties, Journal of Geophysical Research: Solid Earth, 118, 5453-5466. Doi:10.1002/jgrb.50379.

Ji C., K. M. Larson, Y. Tan, K. W. Hudnut, and K. Choi, 2004. Slip history of the 2003 San Simeon earthquake constrained by combining $1-\mathrm{Hz}$ GPS, strong motion, and teleseismic data. Geophysical Research Letters, 31(17), L17608, 10.1029/ 2004GL020448c.

Jianghui Geng, 2015. http://geoapp03.ucsd.edu/gridsphere/gridsphere?cid $=$ Lamjung $\% 2 \mathrm{C}+\mathrm{Nepal}$.

Jianghui Geng, Chuang Shi, Maorong Ge, Alan H. Dodson, Yidong Lou, Qile Zhao, Jingnan Liu, 2012. Improving the estimation of fractional-cycle biases for ambiguity resolution in precise point positioning. Journal of Geodesy, 86, 579-589.

Kouba J., 2009, A Guide to using International GNSS Service (IGS) products, Natural Resources Canada, http://igscb.jpl.nasa.gov/components/usage.html.

Mahmoud Abd Rabbou, Ahmed El-Rabbany, 2015. PPP Accuracy Enhancement Using GPS/GLONASS Observations in Kinematic Mode, Positioning, 6, 1-6.

Mathias Lemmens, 2015. GPS and the 2015 Gorkha Earthquake, GIM International November 2015, 29-31.

Matt King, Stuart Edwards and Peter Clarke, 2002. Precise Point Positioning: Breaking the Monopoly of Relative GPS Processing, Engineering Surveying Showcase 10/2002, 33-34.

Nguyen Ngoc Lau, 2009. How Accuracy GPS Precise Point Positioning can be achieved? Journal of Science and Technology Development, 12(18), 25-31.
Nguyen Ngoc Lau, 2012. Monitoring the Tohoku earthquake on 11. March 2011 by using GPS Technology, International Symposium on Geoinformatics for Spatial-Infrastructure Development in Earth and Allied science, Ho Chi Minh - Vietnam, 279-289.

Nguyen Ngoc Lau, 2013. Precise Point Positioning using GPS and GLONASS measurements, Journal of Geodesy and Cartography (in Vietnamese), 15, 9-17.

Nguyen Ngoc Lau, Duong Minh Au, Nguyen Van Tuan, Dang Van Cong Bang, 2012. Precise point positioning using GPS and GLONASS measurements. Report of ministry-level of project B2010-30-33B201220-33.

Nguyen Ngoc Lau, Tran Trong Duc, Duong Tuan Viet, Dang Van Cong Bang, 2010. Automatic GPS precise point processing via internet. Report of ministrylevel of project B2010-30-33.

Nguyen Ngoc Lau, Ha Minh Hoa, Richard Coleman, 2011. A new technique for processing GLONASS carrier phase measurements over medium length baselines using IGS products, International Journal of Geoinformatics, 7(4), 11-20.

Tomokazu Kobayashi, Yu Morishita and Hiroshi Yarai, 2015. Detailed crustal deformation and fault rupture of the 2015 Gorkha earthquake, Nepal, revealed from ScanSAR-based interferograms of ALOS-2, Earth, Planets and Space, 67, 201p.

UNAVCO, 2015, https://www.unavco.org/highlights/2015/nepal.html. USCG, 2015. https://earthquake.usgs.gov/research/everyone/nepal $2015 /$.

Zumberge J.F., Heflin M.B., Jefferson D.C., Wattkins M.M. and Webb F.H., 1997. Precise point positioning for the efficient and robust analysis of GPS data from large networks, Journal of Geophysical Research, 102(B3), 5005-5017. 